Ann. Biol. anim. Bioch. Biophys., 1979, 19 (4 B), 1369-1380.

\title{
Mechanisms governing onset of ovarian cyclicity at puberty in the lamb
}

\author{
par D. FOSTER, Kathleen RYAN \\ Reproductive Endocrinology Program, \\ Department of Obstetrics and Gynecology and Division of Biological Sciences \\ The University of Michigan, Ann Arbor, Michigan 48109, U. S. A.
}

\begin{abstract}
Summary. The immature female sheep is capable of several aspects of adult reproductive endocrine function long before the onset of puberty. The prepubertal female can ovulate in response to an endogenous gonadotropin surge, which can be elicited by an endogenous estradiol rise which, in turn, can be produced by artificially increasing the rate of pulsatile LH discharge to an hourly frequency. Removal of the ovaries can produce an hourly frequency of LH pulses, but this frequency does not normally occur in the presence of the ovary prior to the beginning of puberty. This implies that the sequence of events leading to the first spontaneous gonadotropin surge is being restrained in the immature female by some mechanism inhibiting the onset of hourly $\mathrm{LH}$ pulses. Because the same levels of circulating estradiol which are capable of suppressing serum LH in the immature ovariectomized lamb are ineffective in this regard in the same females after the age of puberty, it is postulated that the increase in frequency of $\mathrm{LH}$ puises to hourly at the onset of puberty is due to a decrease in the inhibitory feedback action of estradiol on tonic LH secretion. Thus, the anovulatory condition of the immature lamb can be considered as an active state of repression of reproductive function and puberty as a process of derepression. When viewed in this context, a striking similarity exists between the mechanism proposed for transition into adult-hood in the lamb and the postulated mechanism for transition into the breeding season in the adult. Because the onset of fertility in both the lamb at puberty and the adult at the beginning of the breeding season is associated with a pronounced decrease in response to estradiol negative feedback, it suggests either that an important component of the pubertal mechanism is yet operative during adulthood and regulates seasonal fertility, or that « puberty » is an annual process in the adult female sheep.
\end{abstract}

\section{Introduction.}

In a review of over 50 studies of puberty in the female sheep five years ago, Dyrmundsson (1973) indicated that, "There is neither a fixed age, body weight nor time of the year at which ewe lambs experience their first estrus, owing to the complex interaction between these factors and the time of birth ". While we cannot yet account for how the lamb knows when to begin its amorous activities, we are at least starting to understand some of the physiologic mechanisms which are called upon during its transition into adulthood. We are beginning to discover that the lamb may be quite 
capable of carrying out most adult reproductive functions long before the actual time of puberty. In this regard, we are starting to view the anovulatory condition of the immature lamb as an active state of inhibition of reproductive function and the onset of puberty as a process of derepression, And finally, we are beginning to learn that a fundamental element of the pubertal mechanism appears to be retained in the mature female and called upon recurrently to regulate fertility during adulthood.

The foregoing conclusions have been formulated primarily from data obtained in our laboratories, both published and unpublished; the latter will be reported in detail elsewhere. Before presenting some of our recent findings, it is necessary to consider the term «puberty " in the lamb.

\section{Puberty in the female lamb : Event vs. process}

A schematic representation of some of the events which occur in the female sheep during its transition into adulthood, beginning at about 30 weeks of age, is presented in figure 1. Most investigators consider " puberty » in the lamb to be an event, «first estrus $"$ because it is a convenient overt sign that the female has achieved maturity. At this time, the lamb will mate and can become pregnant (Watson and Gamble, 1961 ; Dyrmundsson, 1973). However, upon close examination it is evident that two important ovarian cycles are necessary to pave the way for first estrus. In the immediately preceding cycle, the well known « silent cycle " in which a normal luteal phase occurs, ovulation is not accompanied by sexual receptivity (Foote ef al., 1970 ; Foster et al., 1975a). Recently, we have discovered that yet another cycle precedes the "silent cycle " (fig. 1, inset) (Ryan and Foster, 1978). This brief cycle is less than half the length of the normal cycle and it is initiated by the first LH surge, an event which we consider proclaims that puberty has begun. These considerations have led us to regard " puberty » in the lamb to be a process consisting of a series of developmental events culminating in first estrus, the final stage of sexual maturation.

Viewing puberty as a process, rather than a single event, it has become apparent that 2 separate hypotheses are needed to elucidate the complete mechanism for the transition of the lamb into adulthood. The first hypothesis must account for the onset



FIG. 1. - Schematic overview of the pubertal process in female lamb; additional defails of events leading to the first LH surge (inset) are presented in figure 2. 
of the first LH surge because it is one of the earliest identifiable events in the pubertal process (fig. 1, inset). This hypothesis is the subject of the present report. The second hypothesis, which will not be presented herein, is necessary to explain why onset of fertility is not associated with the onset of the first LH surge. A portion of that hypothesis is discussed elsewhere (Ryan and Foster, 1978).

\section{Hypothesis for onset of pubertal process}

Central to any hypothesis for the initiation of puberty is the mechanism which leads to the first gonadotropin surge because without it, ovulation is not possible. Our hypothesis has been formulated by working backward in time from the first LH surge in an attempt to clarify several of the major events leading to the onset of the surge mode of gonadotropin secretion. Using this approach, we have constructed a hypothetical model for the initiation of the pubertal process. This model, schematized in figure 2 , presents additional details of both known and postulated hormonal relationships which were depicted in figure 1 (inset) during the transition into puberty.

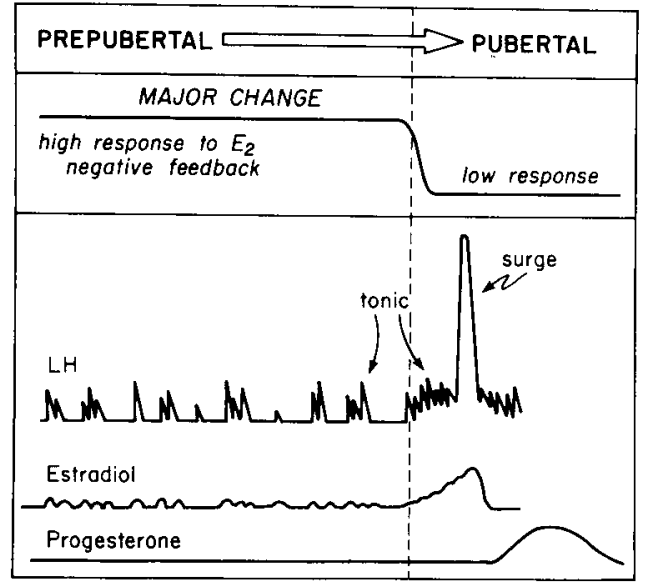

FIG. 2. - Hypothetical model for onset of the pubertal process in the female lamb.

In the prepubertal lamb, the gonadotropin surge mechanism is inactive and spontaneous LH surges do not occur (Foster ef al., 1975a). This mechanism is capable of function, however, since beginning shortly after birth, exogenous estradiol will readily induce an LH surge (Land et al., 1970 ; Squires et al., 1972 ; Foster and Karsch, 1975). If the preovulatory gonadotropin surge system has the potential to function in the immature lamb and yet it remains inoperative until the beginning of puberty, it could be postulated that production of a sustained rise in estradiol to activate the surge mechanism is the final development process which times the onset of the first LH surge. To determine which antecedent event causes the sustained estradiol increase, we must turn to the system controlling fonic LH secretion for we feel that it is the responsibility 
of the mechanism governing pulsatile LH secretion to generate the critical estradiol stimulus at the beginning of puberty.

In contrast to the mechanism governing the surge mode of gonadotropin secretion, the system regulating tonic LH secretion is relatively active throughout the prepubertal period (Foster ef al., 1975a, 1975b). From nearly the time of birth the pattern of basal LH secretion is characterized by marked pulses of LH (fig. 2, left panel) which are about onetenth the size of the preovulatory surge (fig. 2, right panel). Although in general, the frequency of these LH pulses is variable and unpredictable, the number of pulses remains well below one per hour. This low frequency, coupled with the 20to 30-min halflife of circulating LH in the sheep (Geschwind and Dewey, 1968 ; Kaltenbach ef al., 1972), permits the LH baseline to decrease to very low levels between each pulse. We postulate that these infrequent LH pulses cause only transient increases in production of ovarian estradiol in the immature lamb, much the same as they do in the seasonally anestrous adult (Scaramuzzi and Baird, 1977), another anovulatory state in which the ovary is steroidogenically active. These resultant short-lived increases in estradiol prior to puberty, however, are not of sufficient magnitude and/or duration to induce a preovulatory surge of $\mathrm{LH}$, and hence, ovulation.

With the onset of puberty, a sustained rise in the LH baseline occurs over a brief period of a few days (fig. 2, right panel). This sustained rise, we feel, reflects an increase in rate of pulsatile LH discharges to about one per hour, a frequency which does not allow the LH baseline between pulses to return to extremely low levels as did the lower rates of pulsatile release prior to puberty. As a consequence of this frequent and relentless bombardment of the ovary by $\mathrm{LH}$, one or more follicles begin to develop toward the preovulatory stage and the transient rises in estradiol (fig. 2, left panel) become transformed into a steady increase (fig. 2, right panel). Now for the first time, the ovary through its persistent signal, a sustained rise in circulating estradiol, calls upon the dormant preovulatory surge mechanism to evoke the first massive discharge of $\mathrm{LH}$.

What major change takes place at the start of puberty to cause an increase in frequency of $\mathrm{LH}$ pulses, and thus, a sustained elevation in the $\mathrm{LH}$ baseline to drive estradiol production? We postulate that an " escape 》 from inhibitory feedback of ovarian steroids on gonadotropin secretion occurs, more specifically a marked decrease in response of the negative feedback action of estradiol on tonic $L H$ secretion (fig. 2, upper panel). The concept of a decrease in feedback of ovarian steroids on gonadotropin secretion is not novel since this was proposed several years ago as the mechanism for onset of puberty in the female rat (Fevold, 1939 ; Donovan, 1963). As indicaded by recent publications on the developing rat (Odell and Swerdloff, 1974 ; Ojeda et al., 1976 ; Rabii and Ganong, 1976), however, the evidence to support this concept remains controversial. Particularly problematic has been the failure to demonstrate a rise in basal levels of gonadotropins immediately preceding the first gonadotropin surge and the failure to provide strong evidence that the postulated increased sensitivity of the immature rat to estradiol negative feedback cannot be explained equally well by a decreased metabolic clearance rate of this steroid. Because of this, some investigators are now seeking alternative explanations for the mechanism leading to puberty in the rat, one of which is an increasing ovarian sensitivity to low levels of circulating gonadotropins (Odell and Swerdloff, 1974 ; Advis and Ojeda, 1978). Nevertheless, we feel 
the long-held popular theory of puberty, although now being questioned in the rat by some workers, may well be valid when applied to the maturing lamb and that a neuroendocrine, rather than a pelvic (ovarian) "clock » is responsible for the initiation of puberty in the female sheep.

\section{Evidence for hypothesis}

Evidence for the pronounced decrease in feedback inhibition of $\mathrm{LH}$ secretion at the beginning of puberty in the female sheep is presented in figure 3. Patterns of circulating LH are illustrated for lambs in which the ovaries were removed several weeks before the expected age for onset of puberty (about 30 weeks of age). In some of these lambs, a small Silastic capsule containing estradiol was inserted (SC) at ovariectomy. This treatment produced low concentrations of estradiol in the circulation ( $4 \pm 1 \mathrm{pg} / \mathrm{ml}$, lower panel), levels which are comparable to those present in the adult during the luteal phase of the cycle (Hauger et al., 1977). Ovariectomy without estradiol replacement therapy prior io puberty evoked a rapid, several-fold increase in serum LH (fig. 3, middle panel). Treatment with estradiol beginning at the time of ovariectomy, not only prevented the postcastration LH rise, but suppressed circulating $\mathrm{LH}$ to undetectable levels (fig. 3, middle panel). This high degree of suppression of LH secretion by exogenous estradiol was not maintained indefinitely and mean levels of serum LH, by 28 weeks of age, began to rise. The subsequent 20 -fold increase in circulating LH concentrations occurred in the presence of constant levels of serum estradiol. It is important to note that this increase in circulating $\mathrm{LH}$ in estradiol-treated ovariectomized lambs (fig. 3, middle panel) was coincident with the onset of ovulations in intact lambs (fig. 3, histogram, upper panel). Whereas ovarian cyclicity was not initiated in any intact lamb during the period when estradiol was highly effective in suppressing serum LH levels in ovariectomized females (weeks 19-27), first ovulation occurred in 4 of 9 lambs during the same week (week 28) when LH became detectable in estradiol-treated ovariectomized lambs.

Although somewhat obscured by the logarithmic scale, a 50 p. 100 increase in serum LH occurred in untreated ovariectomized lambs during the rise in circulating $\mathrm{LH}$ in estradiol-treated lambs. Such a secondary increase in $\mathrm{LH}$ secretion has also been observed in agonadal children at the age of puberty (Winter and Faiman, 1972 ; Conte ef al. 1975); at present it is difficult to evaluate what contribution, if any, this non-steroid-mediated increase in LH secretion makes at the time of puberty.

If a marked decrease in response to estradiol occurs at the onset of puberty, then a rise in the LH baseline should be evident in the intact female shortly before the first LH surge. Due to the marked pulsatile pattern of LH in the developing female, however, the nature of the critical increase in circulating $\mathrm{LH}$ at the beginning of puberty has been difficult to establish. This is illustrated in figure 4 which depicts changes in serum LH immediately before the first preovulatory LH surge in two individual intact lambs where blood samples were collected at 4-hr intervals during the peripubertal period. In the female shown in the left panel, circulating $\mathrm{LH}$, although variable, returned to low levels on several occasions prior to 6 days before the first LH surge. Thereafter, 
the baseline of LH remained elevated until the time of the massive preovulatory discharge. In contrast, the profile of LH secretion for the lamb on the right illustrates the other extreme observed, namely the failure of circulating $\mathrm{LH}$ to remain increased



FIG. 3. - Relationship between decrease in response to estradiol on tonic $\mathrm{LH}$ secretion (ovx $+\mathrm{E}_{2}$, middle panel) and initiation of ovulation (histogram, upper panel) in the lamb. (First ovulation determined by the appearance of luteal phase levels of serum progesterone.) Vertical arrow indicates time of ovariectomy and beginning of estradiol treatment ; resultant levels of serum estradiol are presented in lower panel. Data are depicted as means ( \pm SE, shaded area) of circulating hormone concentrations obtained thrice weekly. Values for LH below assay defectability are indicated by open circles. Note logarithmic scales are used. (From Foster and Ryan, 1978.) 
until one and one-half days before the first surge. In both cases, however, mean levels of serum LH (shaded horizontal bars) increased 2-fold before the beginning of the LH surge.

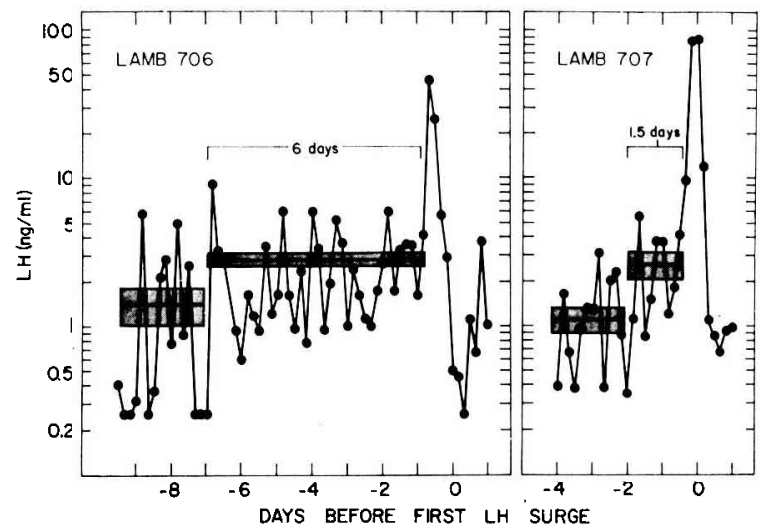

FIG. 4. - Concentrations of circulating LH determined at 4-hour intervals in two female lambs during the peripuberfal period. Horizontal bars indicate means ( \pm SE, shaded area) of individual data points. Note logarithmic scales are used. (From Ryan and Foster, 1978b.)

Such findings indicate that the time course of this increase in the LH baseline may differ somewhat between individuals. Nevertheless, one thing seems evident and that is - the rise is relatively abrupt beginning only a few days before the first LH surge. Although direct observation of patterns of circulating $\mathrm{LH}$ at much closer intervals than $4 \mathrm{hrs}$ is necessary to resolve clearly the issue of whether the pubertal LH rise reflects an increase in rate or amplitude of LH release, data presented below (fig. 5) point to an increase in frequency.

Figure 5 illustrates the pattern of circulating $\mathrm{LH}$, monitored at 20-min intervals over a 6-hr period, in individual lambs before (upper panel) and after (lower panel) puberty. It can be seen that the height of pulsatile LH discharges, although variable ranging from $5-20 \mathrm{ng} / \mathrm{ml}$, is similar at both times. By contrast, whereas the number of LH pulses observed in the immature female was 1-3 per 6-hr period, the number of pulses during the follicular phase of the first estrous cycle, when rapid follicular development and its accompanying rise in serum estradiol occur, ranged from 5-7 per $6 \mathrm{hrs}$. This frequency of pulsatile LH release of about one per hour in the postpubertal lamb does not permit circulating $\mathrm{LH}$ to return to the undetectable levels as does the lower rate of pulses in the prepubertal female.

If is noteworthy that in other studies, ovariectomy of the immature lamb increases the LH pulse rate to hourly (Foster ef al., 1975b). Furthermore, if such a rate of LH pulses is artificially produced in immature females, by acute intravenous injections of purified ovine LH each hour, an LH surge and ovulation occur (Foster and Ryan, 1979). These latter data suggest that the immature female is readily capable of producing the hourly pulses if inhibitory steroids are removed and that if the ovary is exposed to such a frequency of $\mathrm{LH}$ pulses, it is capable of producing the required estradiol stimulus for the LH surge. 
All of the foregoing observations are consistent with the hypothesis that an increase in LH pulse frequency to hourly is the necessary trigger for a sustained estradiol rise and that this frequency of tonic $\mathrm{LH}$ secretion first occurs at the onset of puberty. It is apparent, however, that observations of transient rises in circulating estradiol during periods of infrequent $\mathrm{LH}$ pulses and a sustained estradiol increase during periods of frequent LH pulses (fig. 5) are essential to confirm our hypothesis. Such data remain to be obtained. A more difficult technical challenge will be demonstration of the transition from low frequency to hourly $\mathrm{LH}$ pulses because such a change, if it occurs, may be evident over a period of only a few days before the first LH surge (fig. 4) when no external signs have yet appeared to herald that the female is approaching puberty. Finally, we must account for the role of other pituitary hormones in the pubertal process, particularly FSH. Although extensive measurements of this gonadotropin during maturation have not been reported for the lamb, the data available indicate that circulating FSH levels do not increase at the beginning of puberty (Foster ef al., 1975a ; Fitzgerald and Butler, 1978). Such observations, when combined with those demonstrating that an LH-like stimulus alone produces an increase in estradiol secretion, raise the possibility that FSH is important to maintenance of ovarian function in the prepubertal lamb, but that a rise in circulating $\mathrm{LH}$ is the necessary stimulus leading to final follicular development to the preovulatory stage.

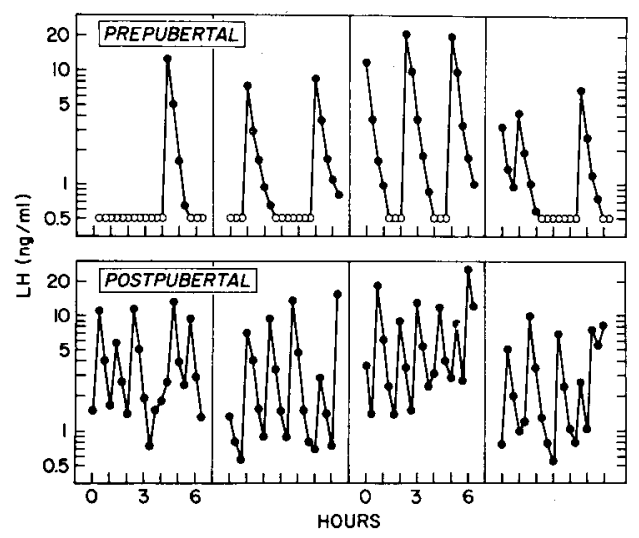

FIG. 5. - Concentrations of circulating LH determined at 20-min intervals over a 6-hour period in individual female lambs before onset of puberty (25 weeks of age, upper panel) and during the follicular phase of the first estrous cycle (lower panel). Values for LH below assay detectability are indicated by open circles. Note logarithmic scales are used. (Replotted from Foster et al., 1975a.)

\section{Similarity of puberty in the lamb and onset of the breeding season in the adult}

Recent collaborative studies with S. J. Legan and F. J. Karsch in our program have revealed that the adult female during its annual transition from anestrus to the breeding season in the early fall (August-September) is associated with a marked reduction in response to estradiol inhibitory feedback on $\mathrm{LH}$ secretion (Legan et al., 
retained during adulthood to serve a new purpose - to regulate seasonal fertility or that « puberty » is a recurrent process in females of seasonally breeding species.

To understand more clearly the similarities and differences between the attainment of maturity and the onset of seasonal breeding will require additional comparative studies of the stimulus which initiates the "escape " from negative feedback in the lamb and in the adult. In the adult female, an external cue, photoperiod, appears to be the primary stimulus. In the lamb, the nature of the stimulus for the critical decrease in response to estradiol feedback at puberty remains to be determined.

\section{Conclusion.}

The scheme of interrelated events which has been presented to account for the transition of the immature female sheep into adulthood is by no means complete. As such it should be regarded as a working hypothesis, which in furn, provides the framework upon which an overall concept of the pubertal process can eventually be built. Although our hypothesis has been formulated from the observation of a marked decrease in estradiol negative feedback on LH secretion during puberty, many questions remain to be answered, both to support this hypothesis and to account for the role of other hormones in the pubertal process. Armed with this working hypothesis, hopefully we can now proceed more rapidly to sort out which factors (age, body weight, environmental cues) initiate the decrease in estradiol negative feedback, and presumably, the onset of adulthood in the female sheep.

4th Workshop on « Development and maturation of the reproductive organs and functions 》 Luynes, France, octobre 1978.

Acknowledgments. - The assistance of our colleagues Drs. Fred J. Karsch, Sandra J. Legan and Robert L. Goodman in the formulation and conduct of these studies is most gratefully acknowledged. We are also indebted to Mr. Douglas D. Doop for valuable technical assistance with animal experimentation, Mr. Robert A. Drongowski for conducting radioimmunoassays, and Drs. Gordon D. Niswender and Leo E. Reichert, Jr., for providing reagents used in radioimmunoassay. These studies were supported by grants from the Biomedical Research Council of The University of Michigan, the Ford Foundation and the NIH (HD-09071 and HD-08333).

Résumé. L'agnelle immature peut manifester plusieurs aspects du fonctionnement endocrinien de la reproduction de l'adulte. L'agnelle prépubère peut ovuler en réponse à une décharge gonadotrope endogène, induite par une élévation du niveau endogène d'estradiol, elle-même artificiellement obtenue en augmentant le nombre de décharges de $\mathrm{LH}$ jusqu'à une par heure. Après castration, les décharges de LH peuvent se produire toutes les heures. Mais en présence des ovaires une telle fréquence des décharges n'existe pas spontanément avant le début de la puberté. Ceci implique que, chez la femelle immature, la séquence des événements amenant à la première décharge gonadotrope spontanée est réprimée par un mécanisme qui empêche l'apparition des décharges de $\mathrm{LH}$ toutes les heures. Comme des taux d'estradiol circulant capables de supprimer la LH sérique chez l'agnelle immature ovariectomisée sont inefficaces chez les mêmes femelles après la puberté, 
on peut penser que, au début de la puberté, l'augmentation de la fréquence des décharges de $\mathrm{LH}$ résulterait d'une diminution de la rétroaction négative exercée par l'estradiol sur la sécrétion tonique de LH. Ainsi, l'absence d'ovulation chez l'agnelle immature serait le résultat de l'existence d'une répression active de la fonction de reproduction ef la puberté résulterait d'un processus de dérépression. Le mécanisme proposé pour expliquer le début de la saison sexuelle chez l'adulte est très comparable. Dans les deux cas on observe une diminution importante de l'efficacité de la rétroaction négative exercée par l'estradiol sur la sécrétion de LH. Ceci suggère qu'une composante importante du mécanisme pubertaire est toujours efficace chez l'adulte ou que la « puberté » est un processus annuel chez la brebis.

\section{References}

ADVIS J. P., OJEDA S. R., 1978. Hyperprolactinemia-induced precocious puberty in the female rat: ovarian site of action. Endocrinology, 103, 924-935.

CONTE F. A., GRUMBACH M. M., KAPLAN S. L., 1975. A diphasic pattern of gonadotropin secretion in patients with the syndrome of gonadal disgenesis. J. clin. Endocr. Metab., 40, 670-674.

DONOVAN B. T., 1963. The timing of puberty. Sci. Basis Med. Ann. Rev., 53-75.

DYRMUNDSSON O. R., 1973. Puberty and early reproductive performance in sheep. I. Ewe lambs. Anim. Breed. Abstr., 41, 273-289.

FEVOLD H. L., 1939. The follicle stimulating and luteinizing hormones of the anterior pituitary. See discussion p. 994. In ALLEN E., DANFORTH C. H., DOISEY E. A., Sex and internal secretions, 2nd Edit., The Williams and Wilkins Co., Baltimore.

FITZGERALD J. A., BUTLER W. R., 1978. Reproductive hormone patterns from birth to puberty in ewe lambs. Biol. Reprod., 18, Suppl. 1, Abstr. 110.

FOOTE W. C., SEFIDBAKHT N., MADSEN M. A., 1970. Puberal estrus and ovulation and subsequent estrous cycle patterns in the ewe. J. Anim. Sci., 30, 86-90.

FOSTER D. L., KARSCH F. J., 1975. Development of the mechanism regulating the preovulatory surge of luteinizing hormone in sheep. Endocrinology, 97, 1205-1209.

FOSTER D. L., RYAN K. D., 1978. Decrease in estradiol negative feedback on tonic LH secretion at puberty in the female lamb. 60th Ann. Meef. Endocr. Soc., Miami Beach, Abstr. 333.

FOSTER D. L., RYAN K. D., 1979. Pulsatile LH secretion in the female lamb : postulated roles prior to and during puberty. 61st Ann. Meet, Endocr. Soc., Anaheim, Abstr. 742.

FOSTER D. L., LEMONS J. A., JAFFE R. B., NISWENDER G. D., 1975a. Sequential patterns of circulating luteinizing hormone and follicle-stimulating hormone in female sheep from early postnatal life through the first estrous cycles. Endocrinology, 97, 985-994.

FOSTER D. L., JAFFE R. B., NISWENDER G. D., 1975b. Sequential patterns of circulating LH and FSH in female sheep during the early postnatal period : effect of gonadectomy. Endocrinology. 96, 15-22.

GAY V. L., BOGDANOV E. M., 1968. Disappearance of endogenous and exogenous luteinizing hormone activity from plasma of previously castrated, acutely hypophysectomized rats : an indirect assessment of synthesis and release rates. Endocrinology, 82, 359-368.

GESCHWIND I. I., DEWEY R., 1968. Dynamics of luteinizing hormone (LH) secretion in the cycling ewe : a radioimmunoassay study. Proc. Soc. exp. Biol. Med., 129, 451-459.

HAUGER R. L., KARSCH F. J., FOSTER D. L., 1977. A new concept for control of the estrous cycle of the ewe based on temporal relationships between luteinizing hormone, estradiol and progesterone in peripheral serum and evidence that progesterone inhibits tonic LH secretion. Endocrinology, 101, 807-817.

KALTENBACH C. C., SCHROFF C. L., KLINDT J. M., DUNN T. G., 1972. Disappearance rates of LH in hypophysectomized ewes. 5th Ann. Meet. Soc. Study Reprod., East Lansing, Abstr. 100.

LAND R. B., THIMONIER J., PELLETIER J., 1970. Possibilité d'induction d'une décharge de LH par une injection d'œestrogène chez l'agneau femelle en fonction de l'âge. C. R. Acad. Sci. Poris, Sér. D, 271, 1549-1551.

LEGAN S. L., KARSCH F. J., FOSTER D. L., 1977. The endocrine control of seasonal reproductive function in the ewe : a marked change in response to the negative feedback action of estradiol on luteinizing hormone secretion. Endocrinology, 101, 818-824. 
ODELL W. D., SWERDLOFF R. S., 1974. The role of the gonads in sexual maturation, 313-341. In GRUMBACH M. M., GRAVE G. D., MAYER F. E., The control of the onset of puberty, John Wiley and Sons, New York.

OJEDA S. R., WHEATON J. E., JAMESON H. E., MC CANN S. M., 1976. The onset of puberty in the female rat : changes in plasma prolactin, gonadotropins, luteinizing hormone-releasing hormone (LHRH) and hypothalamic LHRH content. Endocrinology, 98, 630-638.

RABII J., GANONG W. F., 1976. Responses of plasma "estradiol » and plasma LH to ovariectomy, ovariectomy plus adrenalectomy and estrogen injection at various ages. Neuroendrocrinology, 20, $270-281$.

RYAN K. D., FOSTER D. L., 1978o. Two LH surges at puberty in the female lamb. Biol. Reprod., 18, Suppl. 1, Abstr. 118.

RYAN K. D., FOSTER D. L., 1978b. Necessity for a decrease in negative feedback of ovarian steroids on LH secretion at puberty in the lamb. 60th Ann. Meet. Endocr. Soc., Miami Beach, Abstr. 507.

SCARAMUZZI R. J., BAIRD D. T., 1977. Pulsatile release of luteinizing hormone and the secretion of ovarian steroids in sheep during anestrus. Endocrinology, 101, 1801-1806.

SQUIRES E. L., SCARAMUZZI R. J., CALDWELL B. V., INSKEEP E. K., 1972. LH release and ovulation in the prepubertal lamb. J. Anim. Sci., 34, 614-619.

WATSON R. H., GAMBLE L. C., 1961. Puberty in the merino ewe with special reference to the influence of season of birth on it occurrence. Aust. J. agric. Res., 12, 124-128.

WINTER J. S. D., FAIMAN C., 1972. Serum gonadotropin concentrations in agonadal children and adults. J. clin. Endocr. Metab., 35, 561-564. 